\title{
Some causes of formation of colour during storage of hydrogen-peroxide bleached Norway spruce mechanical pulp
}

\author{
Sofia Enberg, Mats Rundlöf, Magnus Paulsson, Patrik Axelsson, Øyvind Eriksen and Per Engstrand
}

\begin{abstract}
KEYWORDS: Colour, Dye, Iron, Mechanical pulp, Pulp storage, Optical properties, Spectral data

SUMMARY: The discolouration of hydrogen-peroxide bleached Norway spruce mechanical pulp during storage in mill systems was studied and the contributions of process water, iron and dyes were evaluated over the visible spectrum. Washing of the pulp made it less sensitive to storage, possibly due to the removal of extractives, lignin-like substances, iron and pulp fines. Storage in white water gave extensive discolouration with a shoulder in the absorption spectrum at around 550 $650 \mathrm{~nm}$. Most of the colour was associated with pulp fines or filler but some colour was also found in smaller fractions and in the water phase. The addition of ferric ions increased the light absorption coefficient during storage, initially at short wavelengths and then over the whole spectrum, but could not explain the increased absorption at $550-650 \mathrm{~nm}$ and could not be the only cause of the darkening in the mill system. A cationic basic violet dye gave a shoulder in the absorption spectrum similar to that in the mill system, but the absorption in this area did not increase during storage. Model calculations indicate that ferric ions together with violet and red dyes could explain a major part, but not all, of the colour observed in the mill system after storage. The darkening not accounted for at longer wavelengths and around $550-650 \mathrm{~nm}$ is suggested to be related to fines and fillers including dissolved and colloidal substances associated with these particles.
\end{abstract}

\section{ADRESSES OF THE AUTHORS:}

Sofia Enberg (sofia.enberg@ norskeskog.com): Norske Skog Saugbrugs, NO-1756 Halden, Norway / FSCN, Mid Sweden University, SE-851 70 Sundsvall, Sweden Mats Rundlöf (mats@capisco.se): Capisco Science \& Art, SE-602 34 Norrköping, Sweden / FSCN, Mid Sweden University, SE-851 70 Sundsvall, Sweden

Magnus Paulsson (magnus.paulsson@akzonobel.com): AkzoNobel Pulp and Performance Chemicals, SE-445 80 Bohus, Sweden / FSCN, Mid Sweden University, SE-851 70 Sundsvall, Sweden

Patrik Axelsson (patrik.axelsson@norskeskog.com): Norske Skog Saugbrugs, NO-1756 Halden, Norway Øyvind Eriksen (oyvind.eriksen@pfi.no): Paper and Fibre Research Institute, NO-7491 Trondheim, Norway Per Engstrand (Per.Engstrand@miun.se): FSCN, Mid Sweden University, SE-851 70 Sundsvall, Sweden Corresponding author: Sofia Enberg

The cost-efficient and environmental-friendly production of mechanical pulp has become more and more important in recent years. The brightness (whiteness) demands on printing papers have increased (Hill et al. 2010; Johnsen et al. 2010; Kuizhong et al. 2010) and at the same time the market is declining steeply, especially for newsprint grades (Kallioranta, Ostle 2013). A drawback of paper products based on mechanical pulp is discolouration due to radiation and heat (see e.g. Forsskåhl 2000; Paulsson, Parkås 2012). Furthermore, the brightness of bleached mechanical pulp may decrease along the process line from the bleach tower to the paper machine, a known and costly phenomenon (Johnsen et al. 2010; Narvestad et al. 2011). There may be several reasons for this discolouration, which most probably varies from one mill to another and also within one mill from time to time.

In previous studies, the storage of unwashed hydrogenperoxide bleached and well-washed unbleached and hydrogen-peroxide bleached Norway spruce mechanical pulps was studied in a clean system (distilled water) and in a mill system (different types of process waters) (Enberg et al. 2013; Enberg et al. 2014). The darkening was more pronounced when the pulp was stored in process water compared to in distilled water, and an increased storage temperature and prolonged storage times increased the darkening in both systems. Higher pulp consistency therefore gave less darkening in the mill system but had no effect in the clean system. A pH of 5-6 gave the lowest brightness reduction and the smallest increase in light absorption coefficient at $460 \mathrm{~nm}$ compared with a higher or lower $\mathrm{pH}$. In a clean system, hydrogen-peroxide bleached pulps were more sensitive to storage compared to the unbleached pulp at temperatures above $50^{\circ} \mathrm{C}$. The storage of well washed hydrogenperoxide bleached spruce mechanical pulp in white water from a paper machine resulted in colour formation at $550-650 \mathrm{~nm}$. The colour formation was related to the particles in this water (Enberg et al. 2014).

Components in the dilution water may affect the discolouration either directly, upon contact with the pulp or by accelerating the heat-induced reactions. Furthermore, added components may give colour as such, before or after storage, which is retained in the pulp and contributes to the total colour. Narvestad et al. (2013a) reported that freshly added filler clay may induce discolouration by up to seven units of brightness in a similar mechanical pulp. The clay-induced brightness reduction was attributed to the dissolution of iron from the clay. Johnsen et al. (2010) reported a brightness reduction when mechanical pulp was stored together with a non-specified paper additive containing significant quantities of metals. Transition metal ions are known to accelerate the heat and alkali-induced darkening (Gupta 1970; Ni et al. 1997) of mechanical pulps, and iron in ferrous and ferric form increases both the colour and the discolouration when storing high yield pulps (Gupta 1970; Gellerstedt, Pettersson 1980; Gellerstedt et al. 1983; Johnsen et al. 2010; Narvestad et al. 2013a; 
Narvestad et al. 2013b). Metal ions in a concentration typical for tap water (Fe: $\sim 0.3 \mathrm{mg} / \mathrm{l} ; \mathrm{Cu}: \sim 0.04 \mathrm{mg} / \mathrm{l}$ ) are sufficient to reduce the pulp brightness by up to four units and accelerate the heat-induced yellowing of various types of high-yield pulps (Ni et al. 1997). Apart from iron, other metals (e.g. copper) and organic components (e.g. dissolved lignin and extractives) in process waters as well as residual bleaching and paper chemicals may also influence heat-induced discolouration during pulp storage (Gellerstedt, Pettersson 1980; Ni et al. 1997; Rundlöf et al. 2000a; Rundlöf et al. 2000b; Johnsen et al. 2010). In the wet end of a paper machine, the darkening of precipitated calcium carbonate and precipitated calcium sulphate was attributed to the adsorption of wood-based dissolved and colloidal substances from the water phase onto the surface of the fillers (Varhimo et al. 2012). The presence of residual hydrogen peroxide during storage of unbleached pulp may, however, improve the brightness (Ferritius, Lundström 2011).

Generally, the mechanism for heat-induced discolouration of high-yield pulp is proposed to be the formation of chromophores in lignin (Gellerstedt, Pettersson 1980; Gellerstedt et al. 1983; Gratzl 1985; Chong et al. 1991). However, some studies claim that the mechanism also involves carbohydrates forming coloured groups (Luo et al. 1988; Holmbom et al. 1992; Grossmann, Ott 1994; Beyer et al. 1995; Forsskåhl et al. 2000). Hydroquinone and catechol structures in lignin may give rise to rapid discolouration of lignin-rich pulps when exposed to oxygen due to the formation of paraand ortho-quinones as the primary reaction products, and because auto-oxidation is accelerated in the presence of heavy metal ions (Gellerstedt, Pettersson 1980). Phenoxyl radicals have been shown to form during the heat-induced aging of mechanical pulps and these radicals can be transformed into quinones (Gellerstedt, et al. 1983). Transition metal ions, especially ferrous and ferric ions, form strongly coloured complexes with lignin and extractives (Gore, Newman 1964; Gupta 1970; Polcin, Rapson 1972; Meshitsuka, Nakano 1973; Hon, Glasser 1979; Moldenius 1983; Zhang, Gellerstedt 1994; Ghosh, Ni 1998; Ni et al. 1999; Yoon et al. 1999; Forsskåhl 2000; Peart, Ni 2001; Friman et al. 2004) and may therefore contribute to the colour and discolouration of mechanical pulps. These complexes show absorption peaks in different regions of the spectrum, most in the region 500-600 $\mathrm{nm}$, and the absorption bands are generally broad, often covering the whole visible spectrum (Polcin, Rapson 1972; Moldenuis 1983; Ghosh, Ni 1998; Ni et al. 1999; Peart, Ni 2001; Friman et al. 2004).

The purpose of this work is to obtain a more detailed description of the causes behind the formation of colour in mill systems during pulp storage. The influence of different types of paper machine waters on darkening was assessed. The contribution to the colour from iron and dyes was evaluated in addition to which fraction of the stored pulp suspension contained colour after storage. The evaluation was made over the visible range of wavelengths.

\section{Materials and Methods}

\section{Materials}

Pulp

Mechanical pulp made from Norway spruce (Picea abies) was taken from a mill producing super calendered (SC) magazine paper. The hydrogen-peroxide bleached pulp was collected from the wash press after a high consistency bleach tower. The pulp consisted of $93 \%$ thermomechanical pulp and 7\% groundwood pulp. Magnesium hydroxide was used as the alkali source during hydrogen-peroxide bleaching. The pulp was washed in two stages before further treatment in order to reduce the metal and dissolved organic material contents. The first washing stage (Q) was performed using $2.0 \mathrm{~kg} \mathrm{t}^{-}$ 1 diethylenetriaminepentaacetic acid, pentasodium salt (Dissolvine D-40-K from AkzoNobel Functional Chemicals, the Netherlands) at $4 \%$ pulp consistency (p.c.) at $50^{\circ} \mathrm{C}$ for 30 minutes. The second stage (W) was performed with distilled water at $3 \%$ p.c. at $20^{\circ} \mathrm{C}$ for 30 minutes. After each washing stage, the pulp was dewatered on a wire cloth (Monodur PA 112, from Derma, Sweden) and the filtrate recirculated once to avoid loss of fibre and fines. The pulp was then centrifuged to a dry content of about $35 \%$ and stored in a freezer at $-24^{\circ} \mathrm{C}$ until further use. For comparison, some experiments were also performed on the unwashed pulp. Distilled water was used in all pulp washing and laboratory trials described below unless otherwise stated.

\section{Process waters}

Process waters, white water from the paper machine (WW PM) and clear filtrate from the paper machine (CF $\mathrm{PM}$ ) were taken from a mill producing SC paper. The waters were used in the storage trials both as received and

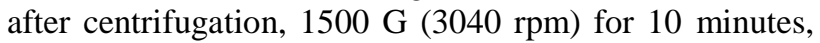
to obtain the dissolved and colloidal phase with a very low content of solid particles such as fines or fillers. Some of the waters were collected on two different occasions (named A and B).

\section{Methods}

\section{Storage procedure}

The pulp was stored in distilled water, in process waters (as received and after centrifugation), in a solution of ferric ions or dye and in a solution of ferric ions and dye. The dye and/or ferric ions were mixed with distilled water before being added to the pulp suspension. Dyes: Red and violet cationic basic dyes, Metric Red 3B 90\% liq. and Metric Violet B both from Brenntag Nordic AB, were used and collected from a mill producing SC paper. The dyes were diluted with distilled water prior to the storage trials. Iron solution: a solution with the concentration $0.258 \mathrm{~g} / \mathrm{l}$ with respect to $\mathrm{Fe}(\mathrm{III})$ was prepared from $\mathrm{Fe}$ (III) chloride. (10\% concentration of $\mathrm{Fe}$, pro analysi, from Merck). The addition of $\mathrm{Fe}(\mathrm{III})$ was $15.6,31.3,62.5,125$ and $250 \mathrm{mg} / \mathrm{kg}$. In the storage trials with ferric ions and ferric ions and dyes, the $\mathrm{Fe}$ (III) addition was $125 \mathrm{mg} / \mathrm{kg}$.

The storage trials were performed at a controlled temperature in a water bath. The pulp was mixed with 
distilled or PM water and stored for five minutes at room temperature before $\mathrm{pH}$ was measured. After measuring the starting $\mathrm{pH}$, the pulp suspension was transferred to a polyethylene bag, and the bag was then sealed and placed in a water bath to simulate pulp storage in a tower. After the storage time had elapsed, the bag was placed in cold water for the pulp to cool down before measuring $\mathrm{pH}$ and proceeding to sheet formation. The storage conditions were: 5 or $24 \mathrm{~h}, 5 \%$ pulp consistency, $65^{\circ} \mathrm{C}$. In every experiment, sheets were made of the pulp and water mixture before storage ( 0 hours) and used as a reference. For the storage time 0 hours, sheet formation started directly after measuring $\mathrm{pH}$.

\section{Iron analysis}

The amount of iron in the water phase of filtrates was determined by spectrophotometry using $\mathrm{HACH}$ Lange DR 2800 - HACH FerroVer iron reagent. Filtrates were obtained after the filtration of pulp suspensions, first on a wire cloth with pore size $112 \mu \mathrm{m}$ (Monodur PA 112, from Derma, Sweden), and then on a cellulose-nitrite filter with pore size $0.45 \mu \mathrm{m}$ (from Millipore, Ireland). "Fe in pulp" in the results part, was calculated on a pulp basis, as the difference of Fe(III) added and the amount of iron measured in the filtrate, together with the iron present in the pulp.

\section{Analyses of waters after wash of pulp}

The waters from the washing of the pulp were analysed for extractives, lignin like substances, total organic carbon and metals. The results from the Q-stage and Wstage were summarized and calculated back on a pulp basis. Chemical analysis: The chemical analyses were performed according to a modified procedure based on the method described by Örså and Holmbom (1994). Details are given in Enberg et al. (2014). Metal analysis: The metal content was analysed after wet combustion with nitric acid $(65 \%$ concentration, trace analysis, from Fluka Analytical) using a microwave system with an inductively coupled plasma (ICP) instrument (IRIS Advantage s/n 10973). The report limits in water $(\mathrm{mg} / \mathrm{l})$ for $\mathrm{Cu}, \mathrm{Fe}$ and $\mathrm{Mn}$ were $0.04,0.08$ and 0.04 respectively. Total organic carbon (TOC): Total organic carbon was measured according to the method NS EN 1484.

\section{Sheet formation}

Laboratory sheets with a grammage of approximately $64 \mathrm{~g} / \mathrm{m}^{2}$ (conditioned at $23^{\circ} \mathrm{C}$ and $50 \%$ relative humidity according to ISO standard method 187:1990) were produced on a small sheet former according to the method described by Karlsson et al. (2012). The sheet former had a 200 mesh wire with a diameter of $112 \mathrm{~mm}$. To increase the retention of material, a retention chemical was added during disintegration. The retention chemical was a polyamine received from AkzoNobel Pulp and Performance Chemicals (Eka ATC 4150), and the addition was $1.5 \mathrm{~kg} / \mathrm{t}$. For detailed experimental procedure, see Karlsson et al. (2012) and Enberg et al. (2014).

\section{Optical measurements}

The measurement of optical properties was made on the top side of the laboratory sheets using a Lorentzen \& Wettre Elrepho SE 070 instrument. ISO brightness, CIE
$L^{*}, a^{*}, b^{*}$ co-ordinates, light scattering $(s)$ and light absorption $(k)$ coefficients were determined according to standard procedures ISO 2470:1999, ISO 5631:2000 and ISO 9416:1998 respectively.

\section{Fractionation procedure}

To try to evaluate the origin (size) of the coloured substances, a simplified separation procedure was performed. After storage or after mixing pulp and water (for storage time 0 hours) one part of the pulp suspension was used for sheet formation as described above and one part was fractionated as illustrated in Fig 1. As a first step, a wire cloth with pore size $112 \mu \mathrm{m}$ (Monodur PA 112, from Derma, Sweden) was used to separate long fibres and middle fractions from smaller parts. The long fibres and middle fractions were not used further. The filtrate was filtrated further using a Munktell number 3 filter with pore size $10 \mu \mathrm{m}$ (from Munktell, Sweden), a glass fibre filter (GFA) with pore size $1.6 \mu \mathrm{m}$ (from Whatman, Germany) and a cellulose nitrite filter with pore size $0.45 \mu \mathrm{m}$ (from Millipore, Irland). The fines material is caught by the Munktell number 3 filter whereas the dissolved and colloidal substances pass through. Larger colloidal substances are caught by the GFA filter and smaller colloidal substances are caught by the cellulose nitrite filter. The dissolved substances pass through the cellulose nitrite filter. The separation procedure is, as already mentioned, simplified and not exact in separating the different parts. The amount of material on each filter was determined and the reflectance measured with the Elrepho instrument using clean filters of the same type as background. Absorbance in the wavelength region $340-750 \mathrm{~nm}$ was determined for the filtrate from the last step using a HACH Lange DR 2800 spectrophotometer. A single absorbance measurement at $280 \mathrm{~nm}$ was also taken using a Hitachi U-1100 spectrophotometer. The iron content in the filtrate passing through the cellulose nitrite filter was measured according to the spectrophotometric method described above.

\section{Modelling the light absorption of unstored/stored pulps}

A model for the light absorption of the unstored and stored ( 5 and $24 \mathrm{~h}$ ) pulp suspensions was prepared by combining the contribution to the visible absorption spectra of iron and the red and violet dyes and adding them to the $k_{\lambda}$ values of pulp in distilled water. It was assumed that the contribution of an additive $\Delta k_{\lambda}$ could be isolated by subtracting the $k_{\lambda}$ of the pulp in distilled water

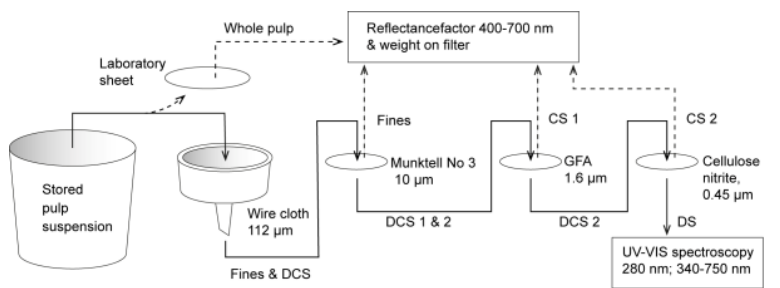

Fig 1 - Fractionation procedure for stored pulp suspensions. DCS $=$ Dissolved and colloidal substances,$C S=$ colloidal substances and DS = dissolved substances. 
from the $k_{\lambda}$ curve obtained for pulp + additive at a given storage time. The model assumes the rule of additivity and was compared to the visible spectra of unwashed and washed pulps stored in white water from the paper machine (WW PM). The model used was:

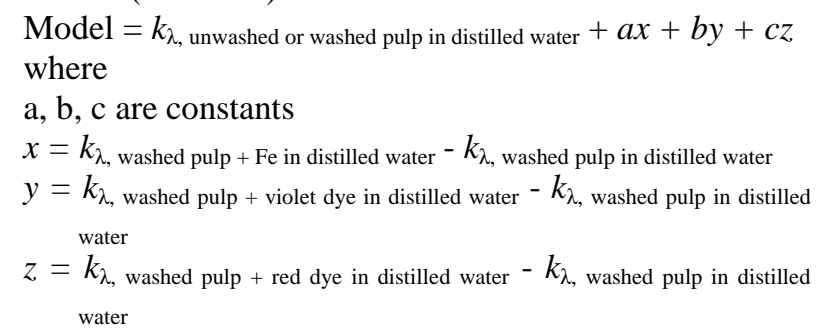

The model was compared with $k_{\lambda}$, pulp in process water for unwashed and well-washed pulp. This straight forward way of modelling means the additives are treated as if they cause additional formation of chromophores independently of the other chromophores formed in the pulp, which are assumed to be exactly the same as in the clean system.

\section{Results and Discussion}

\section{Influence of dilution with different waters on the light absorption}

Fig $2 a$ shows the $k$ spectra after the dilution of unwashed and well-washed pulps with white water from the paper machine (WW PM) or with distilled water. When the pulps were diluted with WW PM there was a shoulder in the light absorption spectra in the region $550-650 \mathrm{~nm}$, present on both sampling occasions (A and B). This shoulder in the absorption spectra coincides with the absorption bands of the dyes used on the paper machine, which are most probably part of the cause of the shoulder in the spectra. When the white water, WW PM, was centrifuged and the upper phase decanted and mixed with the pulps, this shoulder in the spectra could not be seen, which indicates that the colour in this region of the spectrum originate from the particles in the white water, i.e. most probably filler clay (Enberg et al. 2014). For comparison, an unwashed pulp was also included in the evaluation. The light absorption coefficients of the unwashed pulp, diluted with WW PM or distilled water, were somewhat higher than those of the well-washed pulp at all wavelengths in the visible region.

\section{Influence of storage in different waters}

Fig $2 b$ shows the change in $k_{\lambda}$ upon storage, described as $\Delta k=k_{\lambda}$ after storage $-k_{\lambda}$ before storage. After storage for 5 and $72 \mathrm{~h}$, the shoulder in the spectra of the WW PM was still present in the $\Delta k$ spectra, which indicates that additional colour was formed during storage at 550-650 nm. During storage, the difference between unwashed and washed pulp became larger over the visible range of wavelengths. Further, Narvestad et al. (2013a) found that the increase in $k$ at $460 \mathrm{~nm}$ during storage at the same conditions (100 mg/kg Fe(III), $65^{\circ} \mathrm{C}, \mathrm{pH} 5,4 \%$ pulp consistency) was different depending on the pulp used in the trials. In both cases hydrogen-peroxide bleached TMP were used, taken out from the same mill, at the same position and at apparently similar process conditions. For one pulp the increase in $k_{460}$ was $\sim 1.5 \mathrm{~m}^{2} / \mathrm{kg}$ and for the other $\sim 2.8 \mathrm{~m}^{2} / \mathrm{kg}$.

The wash stages removed organic components from the pulp, of which the main part was detected as extractives and lignin-like substances. The wash also reduced the content of some metals. In Table 1, the summarized result measured in the waters from the two wash stages are presented for each component. The values were

recalculated and are given as the amount per $\mathrm{kg}$ of pulp. The total organic carbon (TOC) washed out was $6100 \mathrm{mg} / \mathrm{kg}$. Of this value $2100 \mathrm{mg} / \mathrm{kg}$ was measured as lignin-like substances and $3100 \mathrm{mg} / \mathrm{kg}$ was determined as gravimetric extractives. Only approximately half of the extractives determined gravimetrically were detected in the GC analysis. The iron content was reduced with $6 \mathrm{mg} / \mathrm{kg}$. The light scattering coefficient at $460 \mathrm{~nm}$ of the unwashed pulp was five units higher compared to the washed pulp. The fact that the light scattering coefficient was reduced during wash stages could be due to loss of pulp fines corresponding to 3-4\% of fines (Lindholm 1980, Rundlöf 1996). The light absorption coefficient at $460 \mathrm{~nm}$ was reduced by 0.4 units in the washing stages.

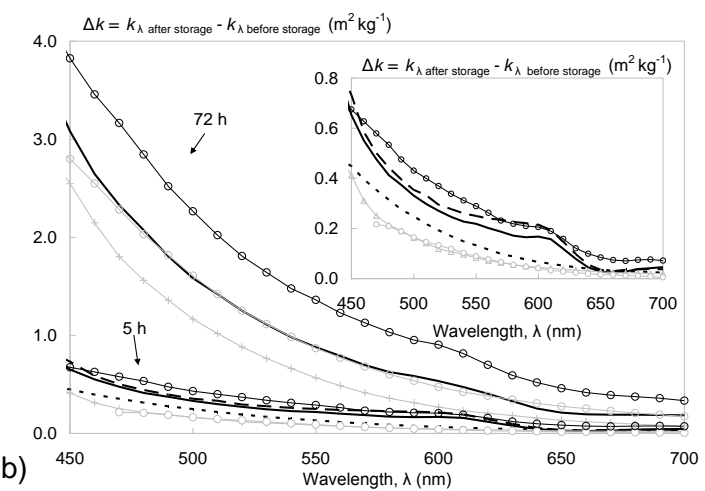

Fig 2 a-b - Spectral data for unwashed or well-washed hydrogen-peroxide bleached Norway spruce mechanical pulp upon dilution and/or storage in different waters. The WW PM was taken out on two different occasions marked $A$ and $B$, and data is also shown for WW PM after centrifugation. a) The light absorption coefficient over the visible spectrum for pulp diluted to $5 \%$ consistency with different waters. b) The difference spectra ( $\Delta k=k_{\lambda}$ after storage $-k_{\lambda}$ before storage) for pulp stored in different waters at $5 \%$ pulp consistency at $65^{\circ} \mathrm{C}$ for 5 hours and 72 hours. The legends are the same as for a). The smaller picture within the figure shows storage for 5 hours with a different scale on the $y$-axis. 
Table1 - The amount of organic material (TOC -total organic carbon), lignin-like substances, extractives and some metals washed out in a two stage $(\mathrm{Q}+\mathrm{W})$ washing procedure together with the optical properties of the Norway spruce mechanical pulp before and after the wash stages.

\begin{tabular}{|c|c|c|}
\hline \multicolumn{3}{|c|}{$\begin{array}{l}\text { Measured in waters after wash }(Q+W) \text { and recalculated } \\
\text { on a pulp basis } \\
\qquad(\mathrm{mg} / \mathrm{kg})\end{array}$} \\
\hline TOC & 6100 & \\
\hline Lignin-like substances & 2100 & \\
\hline Gravimetric extractives & 3100 & \\
\hline Total extractives GC & 1400 & \\
\hline Fatty acids & 150 & \\
\hline Resin acids & 450 & \\
\hline Lignans & 310 & \\
\hline Sterols & 100 & \\
\hline Steryl esters & 170 & \\
\hline Triglycerides & 170 & \\
\hline $\mathrm{Cu}$ & $<0.1$ & \\
\hline $\mathrm{Fe}$ & 6.0 & \\
\hline $\mathrm{Mn}$ & 1.1 & \\
\hline Pulp & $\begin{array}{c}\text { Before wash } \\
\left(\mathrm{m}^{2} / \mathrm{kg}\right)\end{array}$ & $\begin{array}{c}\text { After wash } \\
\left(\mathrm{m}^{2} / \mathrm{kg}\right)\end{array}$ \\
\hline $\begin{array}{l}\text { Light absorption } \\
\text { coefficient at } 460 \mathrm{~nm}\end{array}$ & 2.8 & 2.4 \\
\hline $\begin{array}{l}\text { Light scattering } \\
\text { coefficient at } 460 \mathrm{~nm}\end{array}$ & 82 & 77 \\
\hline
\end{tabular}

The washing obviously removed some colored material, which also made the pulp more sensitive to ageing. This could be pulp fines, extractives, lignin-like substances, iron or some combinations. These data does not identify which component that mainly cause discolouration, but shows that the cleanliness of the pulp may affect the sensitivity to discolouration even when the differences are rather small.

Fig $2 b$ shows that the unwashed pulp gave a larger increase in $k$ over the entire wavelength range for both storage times. This means that one part of the discolouration, measured as delta $k$, originates from the characteristics of the pulp, in this case whether it is washed or not, and the other part depends on the water used for dilution. The difference between using unwashed or a well-washed pulp was greater in the mill system (WW PM) compared to the clean system (distilled water). It seems there was a synergetic effect between the pulp and water upon darkening when unwashed pulp and mill water were stored together. When unwashed pulp was stored in WW PM for 72 hours the increase in $k$ at $460 \mathrm{~nm}$ was $3.5 \mathrm{~m}^{2} / \mathrm{kg}$, corresponding to a decrease in brightness of about 7 units.

\section{Light absorption of finer pulp fractions after storage}

After storage, the finer fractions of the pulp and the dissolved and colloidal substances were studied by carrying out successive filtrations using finer and finer filters. The discolouration was estimated as the change in reflectance of each filter. As a start, fibre- and middle

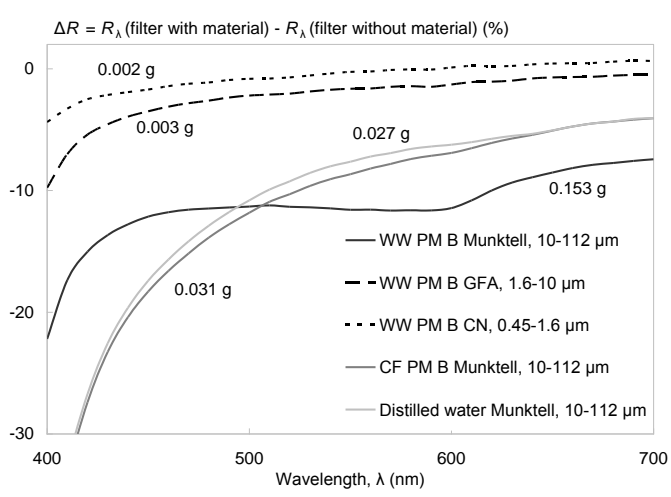

Fig 3 - Change in reflectance factor of a filter paper with and without a stored material from different process waters (reflectance of the sample on a filter-the reflectance of a clean filter) for well-washed hydrogen-peroxide bleached Norway spruce mechanical pulp upon storage at $5 \%$ pulp consistency at $65^{\circ} \mathrm{C}$ for $72 \mathrm{~h}$ in different waters. After storage, the samples were separated according to the method described in the experimental part and Fig 1. The gravimetric amount on each filter is shown in the figure.

fractions were removed using a $112 \mu \mathrm{m}$ wire cloth,leaving most of the particles smaller than the large fines suspended in water. For the pulp stored in WW PM, most of the solid material was retained on the Munktell number 3 filter, as determined gravimetrically. The pore size of this filter is $10 \mu \mathrm{m}$ and the material retained on this filter comprised pulp fines and filler, with most of the dissolved and colloidal material passing through. Most of the colour was also found on the Munktell number 3 filter, Fig 3, measured as the difference in reflectance between the sample on its filter placed over a thick pad of clean filters, and the reference, a pad of clean filters. Fines from pulp stored in clear filtrate from the paper machine or in distilled water also gave colour on the Munktell number 3 filter. The curves representing white water gave a higher reflectance at short wavelengths; this may be due to the light scattering of the clay particles which increases the reflectance. In the case of smaller particles or dissolved molecules, light absorption probably dominates. The finer filters, a glass fibre (GFA) filter with a pore size of $1.6 \mu \mathrm{m}$ and a cellulose-nitrite (CN) filter with a pore size of $0.45 \mu \mathrm{m}$, retained coloured material, presumably dissolved and colloidal material. The weight of the retained material was hardly detectable using this method but despite this, it gave an obvious reduction in reflectance. The absorption measured of the dissolved substances was weak but still had some colour. However, the reflectance curves of these waters did not have the same shapes of the reflectance curve as the WW PM, which showed a decrease in the region around 500 $650 \mathrm{~nm}$ corresponding to the shoulder in the absorption spectra in Fig 2. The results of the fractionation procedure corresponded with the results of the pulp storage trials and indicated that the main part of the colour is associated with the particle phase, i.e. particles the size of fines or filler, including any substances adsorbed onto their surface. 


\section{Adding dyes and/or $\mathrm{FeCl} 3$ to the clean system}

To further investigate the darkening over the spectrum, $\mathrm{FeCl}_{3}$ and two cationic dyes, violet and red, were added to the well-washed pulp in distilled water in different combinations. Dyes can be used to reduce the yellowish shade of mechanical pulps. Basic dyes are often used for mechanical pulps as they get attached to lignin containing fibres and can be used without fixatives (Holmberg 1999). Fig 4 shows the light absorption coefficient at $460 \mathrm{~nm}, k_{460}$, for different additions of $\mathrm{Fe}(\mathrm{III})$, both directly after dilution and after storage for 5 and $24 \mathrm{~h}$. An increased addition of $\mathrm{Fe}$ (III) gave an increase in $k_{460}$, a darker pulp, as expected (Gupta 1970; Moldenius 1983; Narvestad 2013a).

Both before and after storage, adding more iron gave a linear increase in $k_{460}$ up to approx. $60 \mathrm{mg} / \mathrm{kg}$ in the pulp (62 $\mathrm{mg} / \mathrm{kg}$ added). When iron levels were above $60 \mathrm{mg} / \mathrm{kg}$, the increase in $k_{460}$ as more iron was added was still linear but less steep. When the pulp was stored, the $k$-value increased with time as expected, even when no $\mathrm{Fe}(\mathrm{III})$ was added (first point on each curve, $11 \mathrm{mg} / \mathrm{kg}$ is the iron level in the well-washed pulp before the addition of $\mathrm{Fe}(\mathrm{III}))$. When iron levels increased to approx. $60 \mathrm{mg} / \mathrm{kg}$, the slope of the curve for $5 \mathrm{~h}$ of storage was similar to that for direct addition $(0 \mathrm{~h})$, though at levels above $60 \mathrm{mg} / \mathrm{kg}$ the $k_{460}$ continued to increase at a higher rate than for direct addition, though both at a somewhat lower rate than at $\mathrm{Fe}$ (III) additions below approx. $60 \mathrm{mg} / \mathrm{kg}$. After storage for $24 \mathrm{~h}$, the slope of the line at iron levels up to approx. $60 \mathrm{mg} / \mathrm{kg}$ was steeper than for direct addition and $5 \mathrm{~h}$ of storage. When iron levels exceeded approx. $60 \mathrm{mg} / \mathrm{kg}$, the slope of the line was similar at $24 \mathrm{~h}$ to that at $5 \mathrm{~h}$ of storage. After $24 \mathrm{~h}$, the increased darkening due to Fe(III) and storage was evident for all levels of addition.

The results in the present study corresponded with results presented by Jansson and Forsskåhl (1989), where sheets made from chemithermomechanical pulp were impregnated with solutions of metal salts. The darkening increased quicker with low levels of $\mathrm{Fe}$ (III) than when more $\mathrm{Fe}(\mathrm{III})$ was added. These results also correspond with several investigations made in our laboratory.

The steeper increase in $k_{460}$ when lesser quantities of $\mathrm{Fe}$ (III) are added compared to when larger quantities of $\mathrm{Fe}$ (III) are added may indicate either that a higher number of chromophores were formed per added Fe(III) when lesser quantities were added and/or that chromophores more intense in colour were formed. The iron level at "the breaking point" above $60 \mathrm{mg} / \mathrm{kg}$ corresponds to a fibre charge of $\sim 1 \mu \mathrm{mol} / \mathrm{g}$, which is to be compared with the total charge of thermomechanical pulps, which is in the range $85-220 \mu \mathrm{mol} / \mathrm{g}$ (Gellerstedt 2009a). The change in colour formation at $60 \mathrm{mg} / \mathrm{kg}$ does therefore not seem to be related to the carboxylic groups in the pulp e.g. a saturation of carboxylic groups with $\mathrm{Fe}(\mathrm{III})$. The number of lignin monomer units is approx. $1400 \mu \mathrm{mol} / \mathrm{g}$ (calculating lignin as roughly $25 \%$ of the pulp with a molecular weight of a lignin monomer of $180 \mathrm{~g} / \mathrm{mol}$ ). Any functional group that might react with iron to form chromophores would be present only in small quantities in the lignin.

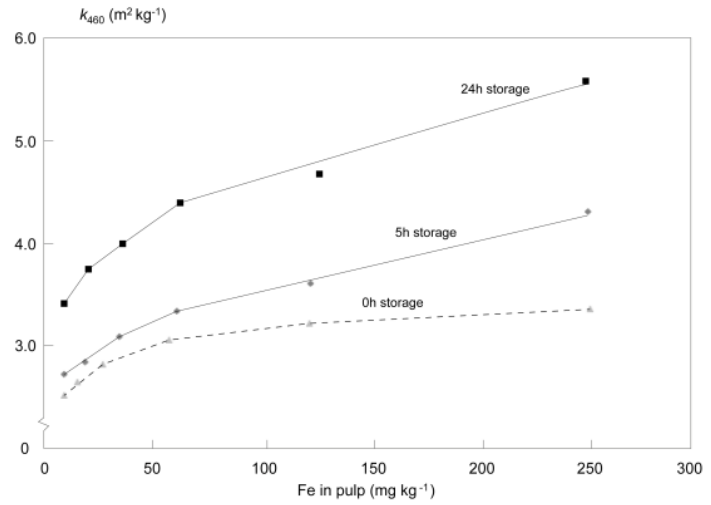

Fig 4 - Light absorption coefficient at $460 \mathrm{~nm}$ for well-washed hydrogen-peroxide bleached Norway spruce mechanical pulp upon dilution and/or storage with various levels of $\mathrm{Fe}(\mathrm{III})$ present. The pulp was stored at or diluted to $5 \%$ pulp consistency and stored at $65^{\circ} \mathrm{C}$ for 5 hours and $24 \mathrm{~h}$.

Using the determined additions based on the data underlined in Fig 4, it is possible to determine how much $\mathrm{Fe}$ (III) would be needed to achieve the actual $k_{460}$ obtained experimentally in some other cases, for the sake of discussion assuming that $\mathrm{Fe}$ (III) was the only cause of the darkening. These estimated additions of Fe(III) to the clean system are shown in Table 2.

The $\mathrm{Fe}$ (III) addition needed to give the $k$ values determined experimentally were higher than the Fe content that could be achieved from fibres and soluble iron in the white water. The iron added via the white water to the well-washed pulp was about $3 \mathrm{mg} / \mathrm{kg}$ for sampling occasion A and about $32 \mathrm{mg} / \mathrm{kg}$ for sampling occasion $\mathrm{B}$, but the $k_{460}$-values after dilution were 3.0 and 2.8 respectively. The increase in $k_{460}$ after 5 hours storage was similar for the two sampling occasions. The dissolved iron in the water phase did not show any clear correlation with the discolouration. When as much as possible of the solid material in the WW PM was dissolved in acid, the iron content was much higher: $317 \mathrm{mg} / \mathrm{kg}$ for WW PM A and $334 \mathrm{mg} / \mathrm{kg}$ for WW PM B. However, an excess of DTPA could not solubilise any of that iron, i.e. the iron content of the water phase was the same as before the DTPA treatment. The filler clay and fines present in the white water were circulated for a period of time and most of the accessible iron may have already been dissolved from the clay. In contrast Narvestad et al. (2013a) show that a fresh clay stored with DTPA may give an iron content in the water phase up to $\sim 30 \%$ of the total iron content in the clay. This "accessible iron" is proposed to cause the clay-induced discolouration (Narvestad et al. 2013a).

Results from measurements of iron in the water phase of filtrates (not shown here) showed that when the Fe(III) solution was added to the pulp, most of the iron became associated with the fibre material and that the reaction was quite fast. This result corresponds with Narvestad et al. (2013b). When Fe(III) was added to the pulp, there was an initial discolouration and a more intense discolouration during storage compared to pulp without Fe(III) added (Fig 4). The same was observed when 
Table 2 - Estimated additions of $\mathrm{Fe}(\mathrm{III})$ that would be needed to achieve the light absorption coefficients at $460 \mathrm{~nm}$ obtained experimentally in the storage trials if $\mathrm{Fe}(\mathrm{III})$ was the only cause of darkening.

\begin{tabular}{lccc|ccc}
\hline & $\begin{array}{c}\text { Fe in pulp } \\
\text { (mg/kg) }\end{array}$ & $\begin{array}{c}\text { Estimated Fe(III) addition } \\
\text { (mg/kg) }\end{array}$ & $\begin{array}{c}\text { Fe pulp in WW PM } \\
\text { (mg/kg) }\end{array}$ & \multicolumn{2}{c}{$\begin{array}{c}\text { Estimated Fe(III) addition } \\
\text { (mg/kg) }\end{array}$} \\
\hline & $\begin{array}{c}\text { Distilled } \\
\text { water }\end{array}$ & $\mathbf{5}$ hours & $\mathbf{2 4}$ hours & & 5 hours & 24 hours \\
\hline Washed pulp & 11 & - & - & $14 ; 431$ & 85 & 70 \\
Unwashed pulp & 17 & 30 & 50 & 49 & 105 & 125 \\
\hline
\end{tabular}

1Sampled on two different occasions (A and B).

pulp was diluted with WW PM, there was an initial discolouration as soon as it was added (Fig 2a) and the pulp darkened more during storage (Fig 2b) compared to pulp stored in distilled water. The darkening when pulp was stored in WW PM could not only have been caused by the dissolved iron added via the WW PM together with the iron already present in the pulp, see Table 2. It may therefore be likely that the darkening was related to the suspended solids present in WW PM, including any substances that may have been adsorbed onto the particles. In the WW PM, iron is probably bound to the fines material making it more sensitive to storage, which may be part of the reason for the extensive darkening. Pulp fines present in white water, including adsorbed dissolved and colloidal substances, may be strongly coloured (Rundlöf et al. 2000b). The way iron is bound to fibres and fine material was not further investigated in this study, but any possible iron associated with the fines in the WW PM was not accessible for DTPA.

When DTPA was added to the WW PM, none of the iron present in the suspended solids, i.e. clay, fines and adsorbed dissolved and colloidal substances, could be released. Therefore, the discolouration was probably not caused by particles being a source of iron for the water phase which could be taken up by the pulp and cause darkening, provided that the DTPA had a higher affinity for iron than the fibre material. The stability constant of iron-DTPA complexes is reported to be much higher than that of iron-lignin complexes (Mao, Ni 2008). The main part of the discolouration during storage could not be attributed to iron in the water phase forming complexes with groups in the fibre material or dissolved and colloidal substances. This is supported by the results of Narvestad et al. (2013b), who show that only a small number of the chromophores formed during storage in the presence of added iron could be eliminated when DTPA was added after storage, despite the fact that much of the iron could be removed. No conclusive evidence was obtained to suggest that coloured complexes with iron are the main contributors to the colour formed during storage. One other possibility may be that the iron ions act as a catalyst in the autoxidation reactions of phenolic structures in the lignin, i.e. catechols and hydroquinones. In these reactions, the primary quinone structures first formed may react further, forming strongly coloured hydroxylated quinones or condensed quinones (Gellerstedt, Pettersson 1980; Gellerstedt 2009b). It is also possible that iron bound to the pulp in a way that do not cause extensive discolouration may rearrange with time to form coloured structures.
In Fig 5, the light absorption coefficients over the visible range of wavelengths are shown for pulp without iron added and for the highest $\mathrm{Fe}(\mathrm{III})$ addition. For clarity, the curves for the $\mathrm{Fe}(\mathrm{III})$ addition $125 \mathrm{mg} / \mathrm{kg}$ were not included. They had a similar curvature and were in between the curves for $0 \mathrm{mg} / \mathrm{kg}$ and $250 \mathrm{mg} / \mathrm{kg}$. As can be seen in the figure, the addition of ferric iron increased the light absorption coefficient over the whole visible spectrum compared to pulp without Fe(III) added. During the storage of the pulp with iron added, there was an increase in $k$ at shorter wavelengths after 5 hours storage, i.e. up to about $600 \mathrm{~nm}$. After storage for 24 hours, the increase in $k$ was noticeable also at longer wavelengths, i.e. over the whole visible region. This corresponds with previous results (Enberg et al. 2013) for well-washed pulp stored in distilled water where the increase in $k$ at longer wavelengths was seen, but not before 72 hours had passed. In the present study, the longest storage time studied was 24 hours, which may explain why we cannot see a clear increase in $k$ at longer wavelengths for the pulp without $\mathrm{Fe}(\mathrm{III})$ added. From these results, it seems that the chromophores causing the increase in $k$ at wavelengths over $600 \mathrm{~nm}$ were formed more rapidly in the presence of iron. However, iron alone does not give any shoulder in the light absorption spectra (cf. Fig $2 b$ ) which corresponds with the results reported by Narvestad et al. (2013a) for a similar system. It was also shown that pulp stored together with new fresh clay did not give a shoulder in the $\Delta k$ spectra (ibid).

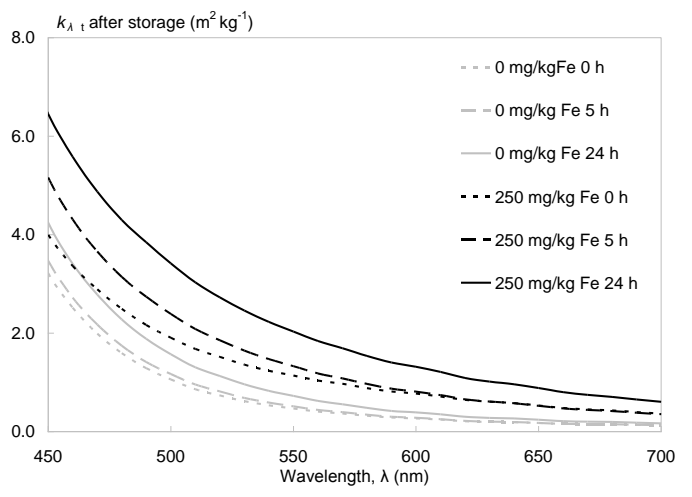

Fig 5 - The light absorption coefficient over the visible spectrum for well-washed hydrogen-peroxide bleached Norway spruce mechanical pulp upon dilution and/or storage with or without $\mathrm{Fe}(\mathrm{III})$ added. The pulp was stored at or diluted to $5 \%$ pulp consistency and stored at $65^{\circ} \mathrm{C}$ for $5 \mathrm{~h}$ and $24 \mathrm{~h}$. 

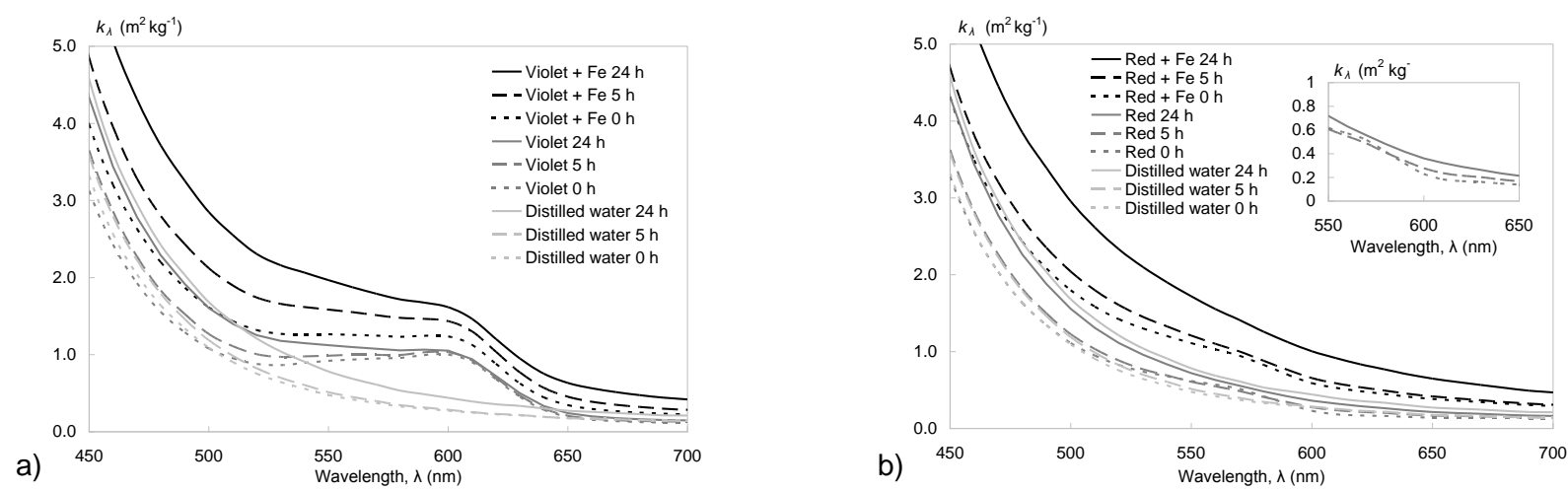

Fig 6 a-b - The light absorption coefficient over the visible spectrum for well-washed hydrogen-peroxide bleached Norway spruce mechanical pulp upon dilution and/or storage at $5 \%$ pulp consistency at $65^{\circ} \mathrm{C}$ for 5 hours and 24 hours. a) Pulp stored with violet dye or with a combination of violet dye and $\mathrm{Fe}(\mathrm{III})$. The $\mathrm{Fe}(\mathrm{III})$ addition was $125 \mathrm{mg} / \mathrm{kg}$. b) Pulp stored with red dye or with a combination of red dye and $\mathrm{Fe}(\mathrm{III})$. The $\mathrm{Fe}(\mathrm{III})$ addition was $125 \mathrm{mg} / \mathrm{kg}$. The smaller picture within Figure b) shows storage of pulp together with the red dye with a different scale on the $x$ and $y$ axes.

Fig 6 shows the $k$ values over the spectrum for washed pulp stored with a red or violet dye alone or in combination with $\mathrm{Fe}(\mathrm{III})$. In the trials with the violet dye (Fig 6a) it can be seen that the shape of the curves resembles the curve of pulp, unwashed and washed, in WW PM. However, for the violet dye the light absorption coefficient in the area 550-650 $\mathrm{nm}$ does not change much during storage. The small increase at wavelengths 550 $600 \mathrm{~nm}$ is due to the pulp, which can be seen in the curves for storage with pulp in distilled water (Fig 6a). The light absorption curves for violet dye together with iron increases over the whole visible spectrum during storage. This general increase was most probably due to the darkening caused by iron as can be seen in Fig 5 .

When the washed pulp was diluted with the red dye, the shoulder in the light absorption spectra tended towards the area of 550-600 nm. During storage for 5 hours, this shoulder tendency could also be observed. This can be seen in the smaller figure within Fig $6 b$ and also during dilution and/or storage with red dye and iron. The light absorption coefficient due to the red dye did not increase with time and was consequently not the cause of the shoulder in the absorption spectra observed with WW PM (cf. Fig 2b). Darkening of this type of dyes (i.e. cationic basic dyes) with time has not been reported to our knowledge, rather the opposite; Liu et al. (2007) reported that the maximum absorbance of a cationic basic dye decreased with increasing temperature in the range 20 $50^{\circ} \mathrm{C}$.

\section{Model calculations of $k_{\wedge}$ compared with experimental results.}

Model calculations of $k_{\lambda}$ were made to estimate the extent to which it is possible to reconstruct the $k_{\lambda}$ curves obtained from experimental data. The model calculations were made using three components: red, violet and $\mathrm{Fe}(\mathrm{III})$, and the respective $\Delta k_{\lambda}$ of these were calculated from experimental data (Fig 4-6). These $\Delta k_{\lambda}$ curves were adjusted to change the contribution of each component, and then added to the $k_{\lambda}$ of pulp in distilled water. The contributions to $k_{\lambda}$ of the dyes were not allowed to increase above the $k_{\lambda}$ values for direct dilution $(0 \mathrm{~h})$, since the $k_{\lambda}$ values of the dyes did not increase with time. Similarly, the contribution to $k_{\lambda}$ by the added Fe(III) was not allowed to decrease with time.

Results of the modelling for direct dilution and 24 hours of storage are shown in Fig 7a and b, modelling was also performed at 5 hours with similar results (not shown). As seen in the figures, it was possible to reconstruct most of the experimental data using the three components added to a pulp, well-washed or unwashed. This indicates that iron added as $\mathrm{Fe}(\mathrm{III})$ in combination with violet dye or red dye may be the main reason for the discolouration of washed and unwashed pulps diluted with WW PM.

Although much of the experimental curves can be modelled using three additives, they are by no means proven to be the main cause of discolouration; there may be other causes of darkening at the same wavelengths. However, the results of the modelling combined with the experimental results gave strong indications. But these three components were not sufficient; chromophores at longer wavelengths do not seem to have been accounted for, neither the fact that the shoulder in the absorption spectra at approx. 550-650 $\mathrm{nm}$ becomes stronger during storage (cf. Fig 2b), i.e. that the shoulder in the absorption spectra was also present in the delta $k_{\lambda}$ spectra. This could not be seen when dyes and/or Fe(III) were added to fibres in the lab system, which could possibly be due to the cleanliness of the lab system; white water from the PM contains dissolved and colloidal substances in the water, or in this case, probably adsorbed onto filler and fines. Some of these substances, possibly in combination with the filler or fines, can provide structures that form chromophores around 550-650 nm. It has been shown that complexes between $\mathrm{Fe}$ (III) ions and lignin or extractive model compounds absorb light in this region of the spectrum, an absorption maximum of $550 \mathrm{~nm}$ for a complex between Fe(III) and D-catechin (Polcin, Rapson 1972); Friman et al. (2004) reported an absorption maximum of $565 \mathrm{~nm}$ for a complex between $\mathrm{Fe}$ (III) and tannin; Gosh and Ni (1998) reported an absorption maximum of $\sim 590 \mathrm{~nm}$ for a complex between Fe(III) and catechol; Gore and Newman (1964) reported absorption maxima of 500-600 $\mathrm{nm}$ for complexes between Fe(III) 

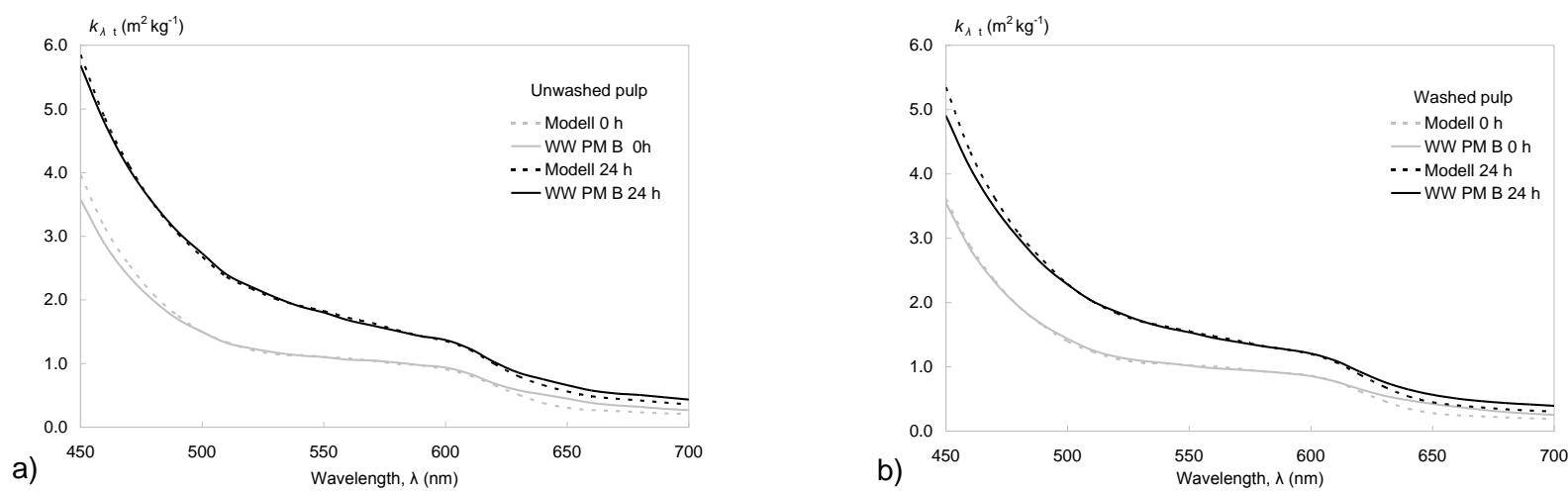

Fig 7 a-b - The light absorption coefficient over the visible spectrum for unwashed and well-washed hydrogen-peroxide bleached Norway spruce mechanical pulp upon dilution and/or storage in white water from the paper machine at $5 \%$ pulp consistency at $65^{\circ} \mathrm{C}$ for 24 hours. The model of $k_{\lambda}$, built by the components red, violet and iron, are included in the figures (for details, see experimental section). a) Model for unwashed pulp. b) Model for well-washed pulp.

and a range of different phenols. Moldenius (1983) attributed an absorption maximum of $585 \mathrm{~nm}$ to ferricphenol complexes, obtained by adding of ferric sulphate to a hydrogen-peroxide bleached groundwood pulp. All of these complexes show broad absorption peaks, and in most cases absorption becomes stronger over the whole visible spectrum. Zhang and Gellerstedt (1994) show that the absorption peak of model compounds of different quinones shift towards longer wavelengths when these are adsorbed onto pulp compared to in solution or on filter paper.

\section{Conclusions}

- One part of the discolouration, $\Delta k$, originate from the characteristics of the pulp, in this case whether it is washed or not, and the other part originates from the water used for dilution, e.g. white water from a paper machine (WW PM) that gave extensive discolouration with a shoulder in absorption spectra at around 550-650 nm.

- Apart from fibres, most of the colour was associated with the particle phase, i.e. fines or filler, including any substances adsorbed onto their surface. The finer fractions and water phase contained some coloured material. The weight of this material was hardly detectable; despite this it gave an obvious reduction in reflectance.

- Both adding more of ferric ions to a well-washed pulp in distilled water and longer storage times increased the light absorption coefficient. The increase begins at short wavelengths, but after longer storage times the increase in $k_{\lambda}$ also becomes noticeable at longer wavelengths (>600 nm).

- Most of the iron became associated with the fibre material and the reaction was quite fast. Adding Fe(III) alone does not give any shoulder in the light absorption spectra.

- The darkening when pulp was stored in WW PM could not only be caused by the dissolved iron added via the WW PM together with the iron already present in the pulp. No conclusive evidence was obtained to suggest that complexes with iron were the main contributors to the colour formed during storage.
- When pulp was stored together with violet cationic dye, the shape of the light absorption curve resembled that of WW PM, though the absorption due to dyes did not increase with time and they were consequently not the cause of the shoulder in the absorption spectra observed after storage in WW PM.

- Model calculations of $k_{\lambda}$ were made using $\Delta k_{\lambda}$ from experimental data of red and violet cationic dyes and $\mathrm{Fe}(\mathrm{III})$. It was possible to reconstruct most of the curves obtained with white water from the paper machine, WW PM. These calculations indicate, but do not prove, that adding $\mathrm{Fe}$ (III) in combination with violet and red dye can cause most, but not all, of the discolouration seen with WW PM. However, these three components were not sufficient; chromophores absorbing at longer wavelengths and the fact that the shoulder in the absorption spectra becomes stronger during storage do not appear to have been accounted for. The additional darkening is suggested to be due to the presence of filler and pulp fines together with some dissolved and/or colloidal substances associated with these particles.

\section{Acknowledgements}

Financial support from the Research Council of Norway and the Knowledge Foundation of Sweden is gratefully acknowledged. We would like to thank Norske Skog for supporting the project and for allowing the publication of the results.

\section{Literature}

Beyer, M., Bäurich, C. and Fischer, K. (1995): Mechanismen der licht- und wärmeinduzierten vergilbung von faserstoffen, Das Papier 49(10A), 8.

Chong, J.M., Nanayakkara, N.P.D. and Whiting, P. (1991): Model compound studies of thermal reversion chemistry, $\mathrm{J}$. Pulp Paper Sci. 17(1), 18.

Enberg, S., Rundlöf, M., Paulsson, M., Johnsen, I.A. and Axelsson, P. (2013): The influence of process conditions during pulp storage on the optical properties of Norway spruce mechanical pulps, Nord. Pulp Paper Res. J. 28(2), 203. 
Enberg, S., Rundlöf, M., Paulsson, M., Axelsson, P., Eriksen, Ø. and Engstrand, P. (2014): The influence of process waters on optical properties during storage of hydrogen-peroxide bleached Norway spruce mechanical pulp, Nord. Pulp Paper Res. J. 29(2), 344-355.

Ferritsius, R. and Lundström, F. (2011): The effect of hydrogen peroxide containing filtrates and storage on unbleached and bleached pulp brightness, Int. Mech. Pulp. Conf., Xian, China, June 26-29, pp. 255-258.

Forsskåhl, I. (2000): Brightness reversion, In: Stenius, P. (ed.), Forest Products Chemistry, Fapet Oy, Helsinki, pp. 278-332.

Forsshåhl, I., Tylli, H. and Olkkonen, C. (2000): Participation of carbohydrate-derived chromophores in the yellowing of highyield pulps, J. Pulp Paper Sci. 26(7), 245.

Friman, L., Höglund, H. and Högberg, H.-E. (2004): Tanniniron impregnated thermomechanical pulp - part I - Effects of extractions and heat on brightness, Nord. Pulp Paper Res. J. 19(2), 229.

Gellerstedt, G. (2009a): Analytical Methods, In: Ek, M., Gellerstedt, G. and Henriksson, G. (eds.), Pulp and Paper Chemistry and Technology - Volume 1 Wood Chemistry and Wood Biotechnology, Walter de Gruyter, Berlin, pp. 195-218.

Gellerstedt, G. (2009b): Mechanical pulping chemistry. In: Ek, M., Gellerstedt, G. and Henriksson, G. (eds.), Pulp and Paper Chemistry and Technology - Volume 2 Pulping Chemistry and Technology, Walter de Gruyter, Berlin, Germany, pp. 35-56.

Gellerstedt, G. and Pettersson, B. (1980): Autoxidation of lignin, Svensk Papperstidning 83(11), 314

Gellerstedt, G., Pettersson, I. and Sundin, S. (1983): Lightinduced and heat-induced yellowing of mechanical pulps, Svensk Papperstidning 86(15), 157.

Ghosh, A. and Ni, Y. (1998): Metal ion complexes and their relationship to pulp brightness, J. Pulp Paper Sci. 24(1), 26.

Gore, P.H. and Newman, P.J. (1964): Quantitative aspects of the colour reaction between iron (III) and phenols, Anal. Chim. Acta 31(2), 111.

Gratzl, J.S. (1985): Lichtinduzierte Vergilbung von Zellstoffen Ursachen und Verhütung, Das Papier 39(10A), 14

Grossmann, K. and Ott, G.A. (1994): Licht- und hitzevergilbung unterschiedlicher papierfasestoffe - ein vergleich, Das Papier 48(10), 623.

Gupta, V.N. (1970): Effect of metal ions on brightness, bleachability and colour reversion of groundwood, Pulp Paper Mag. Can. 71(18), 69.

Hill, J., Sabourin, M., Johansson, L., Mörseburg, K. Axelsson, P., Aichinger, J., Braeuer, P. and Gorski, D. (2010): Combining selective bleaching chemistries and ATMP technology for low energy mechanical pulping at higher brightness, $7^{\text {th }}$ Int. Sem. Fund. Mech. Pulp Res., Nanjing, China, June 20-26, pp. 170-182.

Holmberg, M. (1999): Dyes and fluorescent whitening agents, In: Neimo, L. (ed.), Papermaking Chemistry, Fapet Oy, Helsinki, pp. 305-319.

Holmbom, B., Ekman, R. and Eckerman, C. (1992): Degradation products formed during light and heat treatments of spruce groundwood, J. Pulp Paper Sci. 18(4), 146.
Hon, D.N.S. and Glasser, W. (1979): On possible chromophoric structures in wood and pulps - A survey of the present state of knowledge, Polym. Plast. Technol. Eng. 12(2), 159.

Jansson, J. and Forsskåhl, I. (1989): Color changes in ligninrich pulps on irradiation by light, Nord. Pulp Paper Res. J. 4(3), 197.

Johnsen, I.A., Narvestad, H., Axelsson, P., Enberg, S., Aasarød, K. and Kure, K.-A. (2010): Metal induced brightness loss of peroxide bleached TMP, $7^{\text {th }}$ Int. Sem. Fund. Mech. Pulp Res., Nanjing, China, June 20-26, pp. 211-218.

Kallioranta, S. and Ostle, G. (2013): The next chapter, Paper $360^{\circ} 8(1), 8$

Karlsson, A., Enberg, S., Rundlöf, M., Paulsson, M. and Edström, P. (2012): Determining optical properties of mechanical pulps, Nord. Pulp Paper Res. J. 27(3), 531.

Kuizhong, S., Guigan, F. and Ping, L. (2010): Bleaching of CTMP pulps from nine wood species, $7^{\text {th }}$ Int. Sem. Fund. Mech. Pulp Res., Nanjing, China, June 20-26, pp. 196-201.

Lindholm, C.A. (1980): Comparison of some properties of ground wood and thermomechanical pulp by means of artificial blends of pulp fractions - part 1 - primary results, Paperi Puu 62(10), 593

Liu, H., Yang, S. and Ni, Y. (2007): Using dyes for improving the optical properties of high yield pulps, Pulp Paper Can. 108(10), 25

Luo, C., Putz, L. and Göttsching, L. (1988): Untersuchungen zur licht- und hitzeinduzierten vergilbung von gebleichten ligninhaltigen primär- und sekundärfaserstoffen, Das Papier 42(10A), 55

Mao, C. and Ni, Y. (2008): Effect of metal ion contamination in the process water on the brightness of peroxide- and hydrosulphite- bleached mechanical pulps, J. Pulp Paper Sci. 34(2), 129.

Meshitsuka, G. and Nakano, J. (1973): Effect of metal ion on color of lignosulfonate and thiolignin, Tappi 56(7), 105.

Moldenius, S. (1983): Light absorption coefficient spectra of hydrogen peroxide bleached mechanical pulps, Paperi Puu 65(11), 747

Narvestad, H., Axelsson, P. and Kure, K.-A. (2011): Full scale experiences with magnesium hydroxide based peroxide bleaching and TMP brightness loss at Norske Skog Saugbrugs, $28^{\text {th }}$ Int. Mech. Pulp Conf., Xian, China, June 26-29, pp. 287290.

Narvestad, H., Gregersen, Ø.W. and Kure, K.-A. (2013a): Filler clay induced discolouration of bleached mechanical pulp, Nord. Pulp Paper Res. J. 28(1), 68.

Narvestad, H., Gregersen, Ø.W. and Kure, K.-A. (2013b): Reaction kinetics and mechanisms of filler clay-induced discolouration of bleached mechanical pulp, Nord. Pulp Paper Res. J. 28(3), 331.

Ni, Y., Li, Z. and Van Heiningen, A.R.P. (1997): Minimization of brightness loss due to metal ions in the process water for bleached mechanical pulps, Pulp Paper Can. 98(10), 72.

Ni, Y., Ng, A. and Mosher, M. (1999): A model compound study - The formation of colored metallic extractive complexes 
and their effect on the brightness of TMP pulp, J. Wood Chem. Technol. 19(3), 213.

Paulsson, M. and Parkås, J. (2012): Review: Light induced yellowing of lignocellulosic pulps - Mechanisms and preventive methods, BioRes. 7(4), 5995.

Peart, C. and Ni, Y. (2001): UV-VIS spectra of lignin model compounds in the presence of metal ions and chelants, J. Wood Chem. Technol. 21(2), 113.

Polcin, J. and Rapson, W.H. (1972): Sapwood and heartwood groundwood of western hemlock and jack pine - part III Influence of solvent extractions on the bleaching of pulps, Pulp Paper Mag. Can. 73(1), 86.

Rundlöf, M. (1996): Quality of fines of mechanical pulp, Licentiate thesis ISSN 1104-7003, Royal Institute of Technol., Stockholm.

Rundlöf, M., Htun, M., Höglund, H. and Wågberg, L. (2000a): The importance of the experimental method when evaluating the quality of fines of mechanical pulp, J. Pulp Paper Sci. 26(9), 301.

Rundlöf, M., Htun, M., Höglund, H. and Wågberg, L. (2000b): Mechanical pulp fines of poor quality - Characteristics and influence of white water, J. Pulp Paper Sci. 26(9), 308.
Varhimo, P., Konn, J., Lilland, M. and Paltakari, J. (2012): Brightness reduction of mechanical pulp in the wet end of a paper machine - Method development and validation, Nord. Pulp Paper Res. J. 27(3), 542.

Yoon, B.H., Wang, L.J. and Kim, G.S. (1999): Formation of lignin-metal complexes by photo-irradiation and their effect on colour reversion of TMP, J. Pulp Paper Sci. 25(8), 289.

Zhang, L. and Gellerstedt, G. (1994): Quinoid lignin chromophores and their contribution to photoyellowing, $3^{\text {rd }}$ European workshop on lignocellulosics and pulp, Stockholm, Sweden, August 28-31, pp. 293-295.

Örså, F. and Holmbom, B. (1994): A convenient method for the determination of wood extractives in papermaking process waters and effluents, J. Pulp Paper Sci. 20(12), 361.

Manuscript received February 10, 2014 Accepted April 16, 2014 